\title{
ELECTROCHEMICAL SYNTHESIS AND SPECTROSCOPIC CHARACTERIZATION OF POLY(N-PHENYLPYRROLE) COATINGS IN AN ORGANIC MEDIUM ON IRON AND PLATINUM ELECTRODES
}

\author{
A.K.D. Diaw ${ }^{1}$, D. Gningue-Sall ${ }^{1 *}$, M. Fall ${ }^{1}$, M.M. Dieng ${ }^{1}$ and J.J. Aaron ${ }^{2}$ \\ ${ }^{1}$ Groupe de Recherche en Electrochimie et Sciences des Polymères, Laboratoire de Chimie \\ Physique Organique et d'Analyse Instrumentale (LCPOAI), Département de Chimie, Faculté des \\ Sciences et Techniques, Université Cheikh Anta Diop de Dakar, BP 5005 Dakar-Fann, Sénégal \\ ${ }^{2}$ Interface Traitement Organisation et Dynamique des Systèmes (ITODYS) associé au \\ CNRS.UMR, université de Paris 7-Denis Diderot, 1 rue Guy de la Brosse, 75005 Paris,France
}

(Received October 4, 2007; revised March 4, 2008)

\begin{abstract}
The electrochemical synthesis of poly(N-phenylpyrrole) film was achieved on pretreated iron and platinum electrodes in acetonitrile solutions containing $0.1 \mathrm{M} \mathrm{N}$-phenylpyrrole as the monomer and $0.1 \mathrm{M}$ tetrabutylammonium trifluoromethane sulfonate $\left(\mathrm{Bu}_{4} \mathrm{NCF}_{3} \mathrm{SO}_{3}\right)$ as the supporting-salt. The results showed that a surface treatment by $10 \%$ aqueous nitric acid inhibits iron dissolution without preventing the N-phenylpyrrole oxidation. Very strongly adherent films were obtained at constant-potential, constant-current and cyclic voltammetry. XPS measurements, infrared (FT-IR) and electronic absorption (UV-vis) spectroscopies were used to characterize the iron and platinum-coated electrodes. Finally the anticorrosion properties of the $\mathrm{P} \phi \mathrm{P}$ film were evidenced.
\end{abstract}

KEY WORDS: Polypyrrole, Poly(N-phenylpyrrole), Electropolymerization, Conducting polymers, Corrosion

\section{INTRODUCTION}

Generally, the electropolymerization of heterocyclic compounds like pyrrole, thiophene and their derivatives, is easily anodically performed on inert substrates such as platinum, gold, glassy carbon and graphite under various conditions [1-7]. The films electrodeposited on these electrode surfaces constitute promising materials for practical applications [8-10], owing to their good environmental stability, electrical conductivity, mechanical and luminescence properties. The synthesis and corrosion protection ability of conducting polymer films have been studied since many years [11-14].

These coatings constitute a physical barrier between the corrosive environments and the metal, but also provide anodic protection to substrate. Recently, it has been shown that organic conducting polymers may be used as environmentally friendly-conversion coatings for protecting stainable metals against corrosion [15-16]. Polypyrrole and derivatives are one of the most important classes of conducting polymers in the context. They are insoluble in most of the common solvents and may be used in many chemical environments. However, the electrodeposition of pyrrole and its derivatives like N-phenylpyrrole on oxidizable metals such as iron is more problematic: (i) the first drawback is linked to the strong anodic dissolution of the metal $\left(\mathrm{E}_{\mathrm{eq}}\left(\mathrm{Fe}^{2+} / \mathrm{Fe}\right)=-0.41 \mathrm{~V} / \mathrm{SCE}\right)$ [17] before the oxidation of the monomer [18], which prevents the occurrence of the electropolymerization reaction on the iron electrode; (ii) the second problem is generally due to the decomposition of some salts used at metal-film interfaces, as described by Ferreira et al [19]; and (iii) the last reason is due to the fact that the electropolymerization process of most of the monomers is easier in acid nucleophilic solvents like acetonitrile; whereas these media are thermodynamically favourable to the dissolution of iron. The only possible solution of this problem is to optimize the experimental conditions

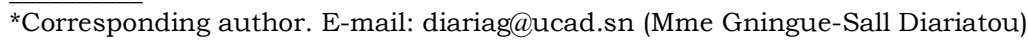


permitting to slow down the dissolution rate of the metal without stopping the electropolymerization process. Two strategies are generally employed: (i): select the convenient medium parameters (solvent, salt...), and (ii): pretreat the metal surface by using inhibiting solutions like dilute aqueous nitric acid $(10 \%)$ as described by Ferreira et al. [15]. Since Skotheim et al. realized in 1982 the electrodeposition of polypyrrole on oxidizable metals in organic media [20], lot of efforts have been devoted to achieve the protection of oxidizable metals by using organic conducting polymers. Stevens et al. [21] obtained a fibrillar polypyrrole on several types of metallic electrodes ( $\mathrm{Ti}, \mathrm{Al}, \mathrm{Fe} . .$.$) by using a solution of tetraethylammonium$ tosylate in propylene carbonate. Also, the feasibility of the electrodeposition of polypyrrole in the presence of nitrate as electrolyte, but not with $\left(\mathrm{BF}_{4}^{-}, \mathrm{ClO}_{4}{ }^{-}\right.$or $\left.\mathrm{SO}_{4}{ }^{-}\right)$has been previously reported [22]. Furthermore, Ferreira et al. [15] obtained a very adherent, thickness-controlled polypyrrole by chronopotentiometry in various aqueous media containing $\mathrm{Na}_{2} \mathrm{SO}_{4}, \mathrm{~K}_{2} \mathrm{C}_{2} \mathrm{O}_{4}$ or $\mathrm{KNO}_{3}$. In our laboratory, the 3-methoxythiophene (MOT) electropolymerization was performed on $\mathrm{Pt}$ and $\mathrm{Fe}$ electrodes in an aqueous micellar medium containing sodium dodecylsulfate and $10^{-3} \mathrm{M}$ bithiophene (BT). The oxidation potential of MOT was found to be lower than that of unsubstituted thiophene, because of the electrodonating properties of the methoxy group. Also, the electrocatalytic effect of BT in the electropolymerization process, allowing the electrodeposition of PMOT-PBT coatings on iron [17] has been evidenced. Electroactive, homogeneous and adherent poly (3-methoxythiophene)-polybithiophene (PMOT-PBT) composite films composed of oligomers, including PMOT and PBT, and traces of copolymers, have been electosynthesized.

In the case of $\mathrm{N}$-substitued pyrrole, some authors have already described its electrochemical polymerization $[3,5,7,11]$. Indeed, in our previous works $[23,24]$, we studied the poly $(\mathrm{N}$ phenylpyrrole) electrosynthesized on Pt, in organic and micellar media. However, to the best of our knowledge, the use of iron electrode for the electrodeposition of poly(N-phenylpyrrole) has not been reported.

The goal of this study is to realize the electrodeposition of a homogeneous and strongly adherent poly(N-phenylpyrrole), (referred hereafter as $\mathrm{P} \phi \mathrm{P}$ ) on iron and platinum substrates and to investigate its electrochemical and spectroscopic properties. The aim is to see how the coverage of the oxidizable metals like iron by $\mathrm{P} \phi \mathrm{P}$ could prevent corrosion. The use of phenyl substituent is motived by its electrondonating properties.

\section{EXPERIMENTAL}

Acetonitrile, $\mathrm{Bu}_{4} \mathrm{NCF}_{3} \mathrm{SO}_{3}$ and $\mathrm{N}$-phenylpyrrole was purchased from Aldrich and used as received. The electropolymerization was performed in organic medium, containing $0.1 \mathrm{M}$ of $\mathrm{Bu}_{4} \mathrm{NCF}_{3} \mathrm{SO}_{3}$ and $0.1 \mathrm{M}$ of N-phenylpyrrole.

The electrochemical measurements were performed in a one-compartment three electrodecell with an EG \& G Princeton Applied Research Potentiostat. The working electrode was either a platinum disc $\left(5 \mathrm{~mm}\right.$ diameter) or rectangular iron sheets $\left(1 \mathrm{x} 4 \mathrm{~cm}^{2}\right)$. Before use, the iron electrode was treated with $10 \%$ (wt.) nitric acid. The films were deposited by the potentiodynamic, potentiostatic or galvanostatic methods, and characterized by UV-visible, FTIR and XPS spectroscopies. Absorption spectra were recorded for films electrodeposited on ITO (indium-tin oxide) sheets, using a Lambda 2 Perkin Elmer UV-vis spectrometer. IR spectra were recorded on a Nicolet 60 SX FT-IR spectrometer. The X-photoelectron (XPS) analysis was carried out with a VG Escalab MK1 apparatus. 


\section{RESULTS AND DISCUSSION}

\section{Electrodeposition of the films on Pt}

Upon scanning repetitively the potential between 0 and $1.3 \mathrm{~V}$ vs. SCE at $100 \mathrm{mV} \mathrm{s}^{-1}$ in the selected organic medium, we observed the electrodeposition and growth of a thick, green $\mathrm{P} \phi \mathrm{P}$ film on the Pt electrode surface. As can be seen in Figure 1, the voltammogramms are characterized by anodic peaks, located at $0.7 \mathrm{~V} / \mathrm{SCE}$, corresponding to the film oxidation, in addition to one relative cathodic peak appearing at $0.55 \mathrm{~V}$ which is assigned to the reduction of the oligomers already formed.

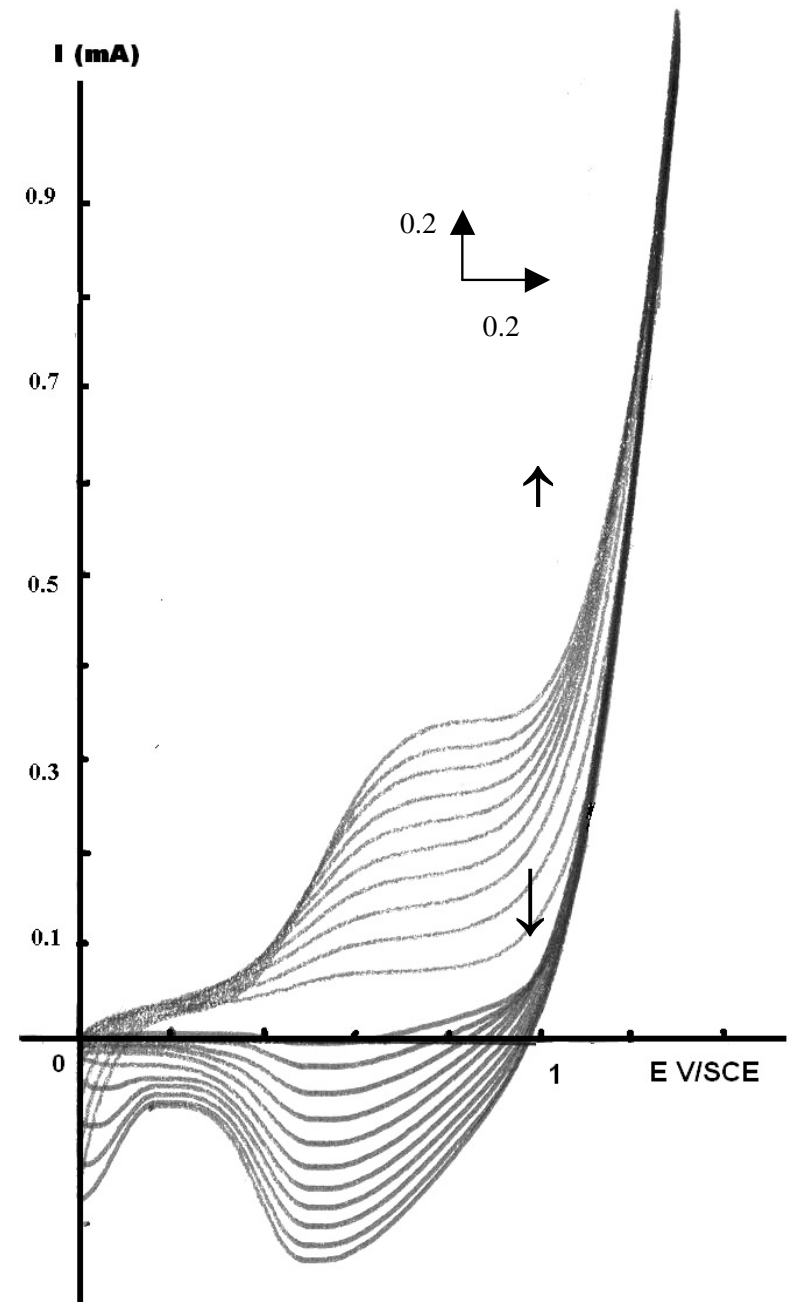

Figure 1. Voltammogramms of the electropolymerization of N-phenylpyrrole $\left(\begin{array}{lll}0.1 & \mathrm{M}\end{array}\right)$ in acetonitrile solution containing $\mathrm{Bu}_{4} \mathrm{NCF}_{3} \mathrm{SO}_{3} 0.1 \mathrm{M}$ at $\mathrm{v}=100 \mathrm{mV} / \mathrm{s}$ on Pt electrode. 
The electropolymerization of N-phenylpyrrole was also performed by chronoamperometry at potentials of $1.10,1.15,1.20,1.30$, and $1.40 \mathrm{~V} / \mathrm{SCE}$ (Figure 2). Chronoamperometric curves obtained on Pt electrode show the three phases described in the literature [25]: phase of nucleation (1), coupling phase (2) and phase of growth and doping (3). The electropolymerization occurs when the potentials raises $1.15 \mathrm{~V} / \mathrm{SCE}$. From this value, the polymerization currents are constant after the nucleation growth phase and homogeneous, adherent, electroactive $\mathrm{P} \phi \mathrm{P}$ films are formed on the Pt electrode.

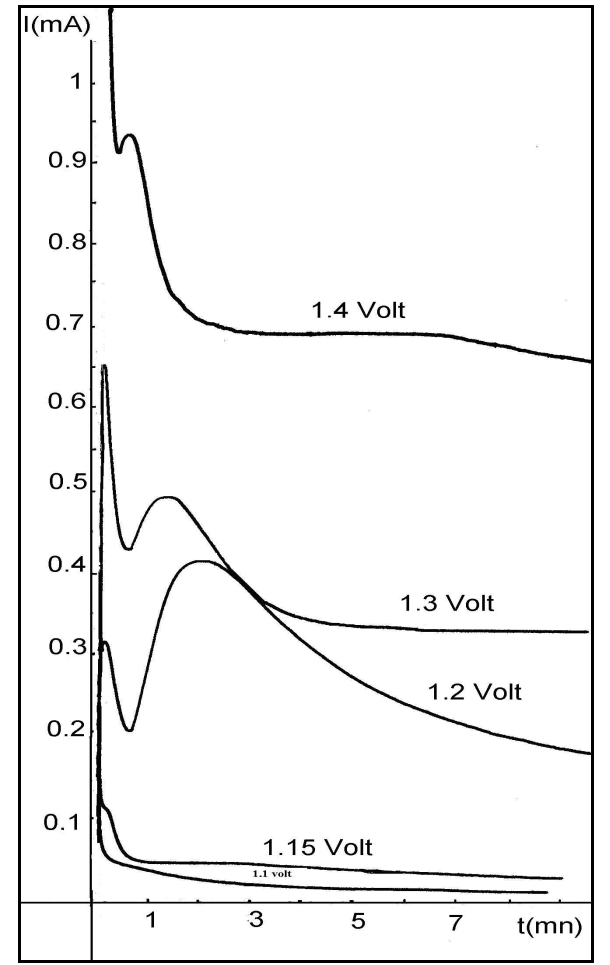

Figure 2. Chronoamperometric curves of the electropolymerization of N-phenylpyrrole $(0.1 \mathrm{M})$ in acetonitrile solution containing $\mathrm{Bu}_{4} \mathrm{NCF}_{3} \mathrm{SO}_{3} 0.1 \mathrm{M}$, on Pt electrode.

Finally, we realized the electrosynthesis of $\mathrm{P} \phi \mathrm{P}$ by the galvanostatic mode. The chronopotentiometric curves obtained at current densities ranging from 0.125 to $0.5 \mathrm{~mA} / \mathrm{cm}^{2}$ (Figure 3) shows that the N-phenylpyrrole polymerization process begins at very low current densities, leading to homogeneous and adherent films. For current densities close to $1 \mathrm{~mA} / \mathrm{cm}^{2}$, the corresponding curves are characterized by a first plateau potential at around $0.9 \mathrm{~V} / \mathrm{SCE}$ corresponding to the formation of $\mathrm{P} \phi \mathrm{P}$ films, followed by a rapid potential increase and a second plateau at $2.2 \mathrm{~V} / \mathrm{SCE}$. In this case, the films formed were not electroactive, because the deposit was much degraded (Figure 3).

The $\mathrm{P} \phi \mathrm{P}$ oxidized and reduced forms were found to be insoluble in the common solvents, indicating probably a high polymerization degree. 


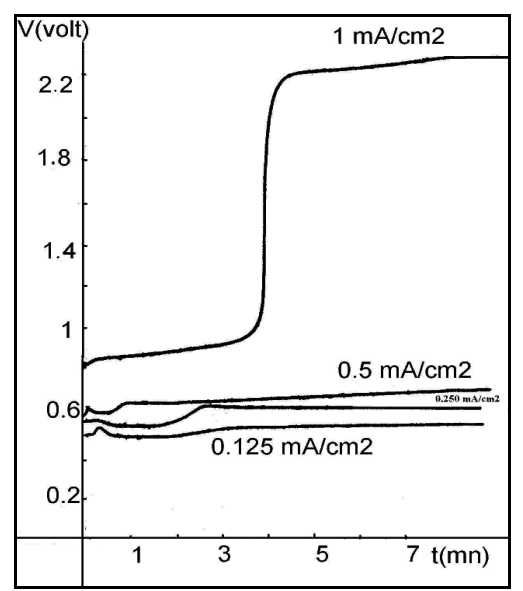

Figure 3. Chronopotentiometric curves of the electropolymerization of $\mathrm{N}$-phenylpyrrole $(0.1 \mathrm{M})$ in acetonitrile solution containing $\mathrm{Bu}_{4} \mathrm{NCF}_{3} \mathrm{SO}_{3} 0.1 \mathrm{M}$ on Pt electrode.

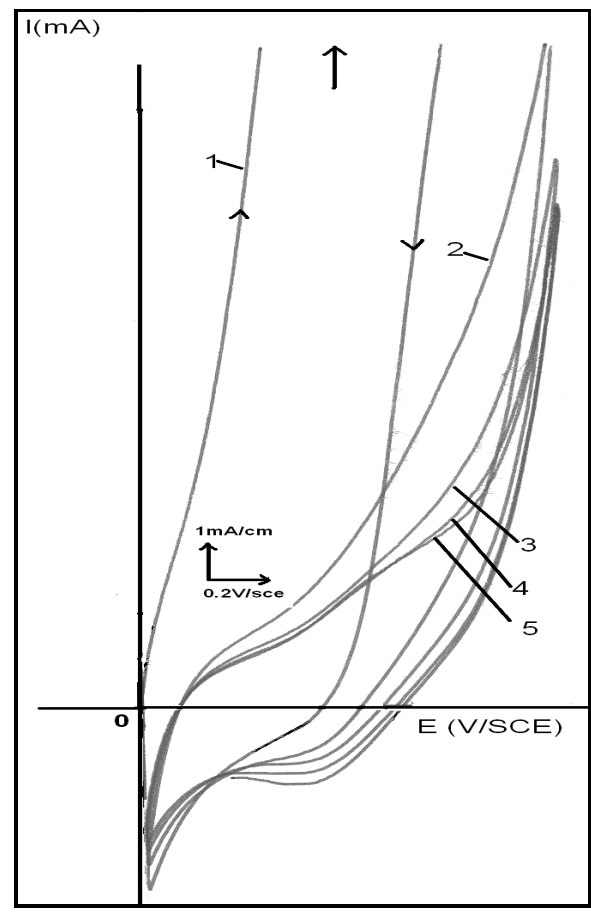

Figure 4a. Voltammograms of the growth of $\mathrm{P} \phi \mathrm{P}$ (1-5 cycles) in acetonitrile solution containing $0.1 \mathrm{M}$ of $\mathrm{N}$-phenylpyrrole and $0.1 \mathrm{M}$ of $\mathrm{Bu}_{4} \mathrm{NCF}_{3} \mathrm{SO}_{3}$ on a Fe electrode. Scan rate: $100 \mathrm{mV} / \mathrm{s}$.

Bull. Chem. Soc. Ethiop. 2008, 22(3) 


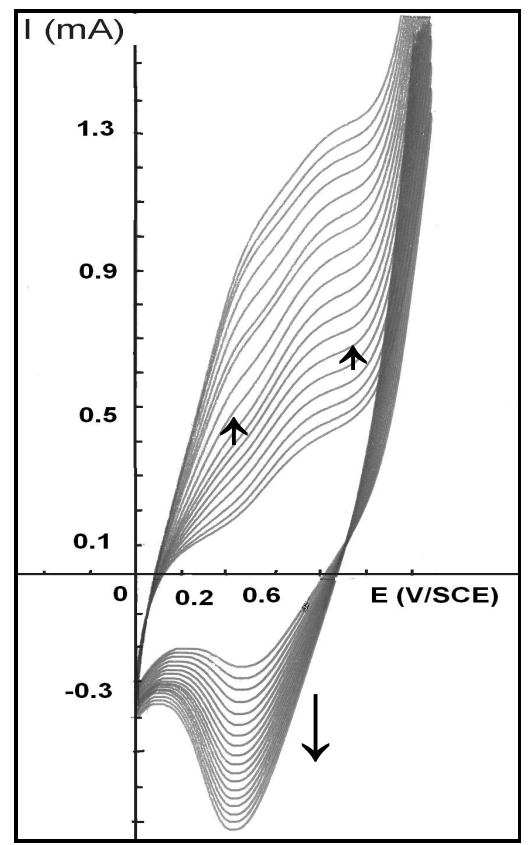

Figure $4 \mathrm{~b}$. Voltammograms of the growth of $\mathrm{P} \phi \mathrm{P}$ after 5 cycles in acetonitrile solution containing $0.1 \mathrm{M}$ of $\mathrm{N}$-phenylpyrrole and $0.1 \mathrm{M}$ of $\mathrm{Bu}_{4} \mathrm{NCF}_{3} \mathrm{SO}_{3}$ on a Fe electrode. Scan rate: $100 \mathrm{mV} / \mathrm{s}$.

Electrodeposition of P $\phi P$ on Fe

We investigated the feasibility of the $\mathrm{N}$-phenylpyrrole electropolymerization on the iron electrode in an acetonitrile solution containing $0.1 \mathrm{M}$ of $\mathrm{Bu}_{4} \mathrm{NCF}_{3} \mathrm{SO}_{3}$ and $0.1 \mathrm{M}$ of $\mathrm{N}$ phenylpyrrole. The potential was scanned between 0 and $1.3 \mathrm{~V} / \mathrm{SCE}$ at $100 \mathrm{mV} \mathrm{s}^{-1}$ (Figure 4).

As shown in Figure $4 \mathrm{a}$, when the potential scanning started at $0 \mathrm{~V} / \mathrm{SCE}$, a broad peak appeared at around $0.4 \mathrm{~V} / \mathrm{SCE}$ due to the iron oxidation process $[15,17,18]$. In the first cycle, we note a broad band assigned to the iron dissolution. After $1 \mathrm{~V} / \mathrm{SCE}$, the oxidation of the monomer starts and the substrate is partially covered by the film. During the reverse scanning, the $\mathrm{P} \phi \mathrm{P}$ already formed is reduced. In the following cycles, the current intensity diminishes because the electrode is more significantly protected. After 5 cycles, the current density increases, showing the regular formation and growth of the $\mathrm{P} \phi \mathrm{P}$ film (Figure $4 \mathrm{~b}$ ). The iron corrosion phenomena are attenuated because the electrode is entirely covered by the film and then passivated. The peaks noted between 0.4 and $0.8 \mathrm{~V} / \mathrm{ECS}$ are attributed to the polymer oxidation (doping). They however may include the oxidation of some ferrous ions entrapped in the polymer matrix during the reduction, into ferric ions. In the cathodic part, we observe a decrease in the current density due to the reduction of the polymer (dedoping) and probably of the iron oxides and/or hydroxides formed because of the presence of residual amounts of water in acetonitrile (Figure 4a). The voltammogramms obtained on Fe after 5 cycles become quasi similar to those recorded on the Pt electrode.

Figure 1 and $4 \mathrm{~b}$ show that the current densities are higher in the modified iron electrodes, relative to platinum modified electrodes. This feature may indicate that the film obtained on iron 
are more conductive than those obtained on platinum, due to the presence of $\mathrm{Fe}^{2+}$ and/or $\mathrm{Fe}^{3+}$ ions in the former case. This result is similar to that obtained in the case of poly(3methoxythiophene) electrodeposited on iron [16].

\section{Electrochemical properties of the films}

The electrochemical properties of $\mathrm{P} \phi \mathrm{P}$, electrodeposited by cyclic voltammetry ( 20 cycles) on $\mathrm{Pt}$ and $\mathrm{Fe}$ electrodes, were studied in acetontrile solution containing $0.1 \mathrm{M}$ of $\mathrm{Bu}_{4} \mathrm{NCF}_{3} \mathrm{SO}_{3}$. The voltammogramms exhibit well defined, reversible redox peaks at $0.70 \mathrm{~V} / \mathrm{SCE}$ and at 0.55 $\mathrm{V} / \mathrm{SCE}$ on Pt in the anodic and cathodic regions, respectively. On Fe, the corresponding peaks are located at 0.8 and at $0.5 \mathrm{~V} / \mathrm{SCE}$ (Figure 5). These peak intensities are found to vary linearly with the scan rate and this result points to a surface confined redox system [4, 19].

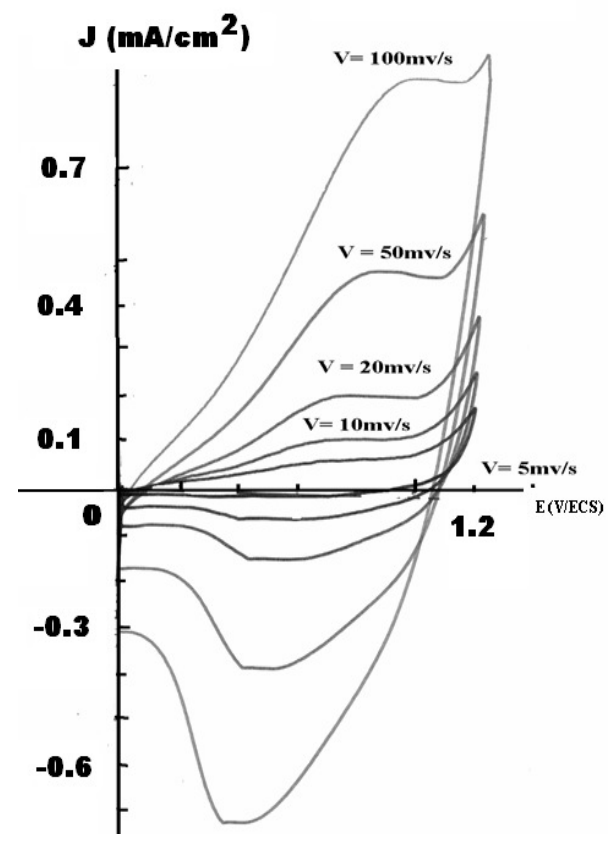

Figure 5. Electroactivity in acetonitrile solution containing $\mathrm{Bu}_{4} \mathrm{NCF}_{3} \mathrm{SO}_{3} 0.1 \mathrm{M}$ of a $\mathrm{P} \phi \mathrm{P}$ film obtained on Fe by the cyclic voltammetry ( 20 cycles).

\section{Films characterizations}

The structure of N-phenylpyrrole and $\mathrm{P} \phi \mathrm{P}$ films, obtained on $\mathrm{Pt}$ and $\mathrm{Fe}$ electrode, was studied using UV-visible, FT-IR and XPS spectroscopy.

$U V$-VIS absorption spectroscopy. The UV-visible absorption spectra of oxidized and reduced $\mathrm{P} \phi \mathrm{P}$ films electrosynthesized on ITO plaques were recorded. The $\mathrm{P} \phi \mathrm{P}$ main absorption band at $357 \mathrm{~nm}$, more important in reduced form, can be attributed to the $\pi-\pi^{*}$ delocalized transition in the polymer. The second larger band in the region of 520-620 nm, which disappeared in the reduced form, is assigned to the $\pi-\pi *$ transition of the conjugated 
cationic segments of the polymer with the salt (polaronic or bipolaronic forms). These wavelengths values are close to those reported for polypyrrole and its derivatives [5].

FT-IR spectroscopy. The main bands of the monomer and the polymer were obtained, respectively, on $\mathrm{KBr}$ pallet and on $\mathrm{Pt}$ and $\mathrm{Fe}$ electrodes (Table 1). The assignments are in good agreement with those already found in the literature [5, 14, 26-28]. The two strong bands, visible at 1015 and at $719 \mathrm{~cm}^{-1}$ in the monomer spectrum and characteristic of unsubstituted pyrrole 4-adjacent hydrogen vibrations $\left(\mathrm{v}_{\mathrm{C}-\mathrm{H}}\right)$, disappeared in those of the polymers. In addition to the band observed near $1030 \mathrm{~cm}^{-1}$, assigned to the $\mathrm{C}-\mathrm{H}$ deformation vibration for 2-adjacent hydrogen in the polymer spectra, proved the polymerization in the 2,5 positions [26]. According to the vibrations found in the spectra and shown in Table 1, we can conclude that films obtained in $\mathrm{Pt}$ and $\mathrm{Fe}$ electrodes have the same structure.

Table 1. Vibrations modes and corresponding frequencies $\left(\mathrm{cm}^{-1}\right)$ in $\mathrm{N}$-phenylpyrrole and poly-Nphenylpyrrole spectra obtained on Pt and Fe.

\begin{tabular}{|c|c|c|c|}
\hline Monomer & Film on Fe & Film on Pt & Attributions \\
\hline $3151,3141,3113,3102$ & & & $\mathrm{vC}$-H harmonic aromatic \\
\hline $3063,3046,3020$ & & & $\mathrm{vC}-\mathrm{H}$ pyrrole harmonic \\
\hline -------- & 2964,2877 & $2976,2883,2809$ & vC-H pyrrolidinone harmonics \\
\hline 1694 & 1718 & 1717 & $v \mathrm{C}=\mathrm{O}$ \\
\hline 1604,1591 & 1596 & 1596 & $v \mathrm{C}=\mathrm{C}$ aromatic \\
\hline 1513 & 1496 & 1497 & $\vee \mathrm{C}=\mathrm{C}$ aromatic \\
\hline $1558,1470,1460,1401$ & 1384 & $1545,1385,1327$ & $v \mathrm{C}=\mathrm{C}, \mathrm{vC}-\mathrm{N}$ pyrrole \\
\hline $1256,1189,1164$ & 11531264 & 1258,1152 & $\delta \mathrm{C}-\mathrm{H}$ aromatic out of plane \\
\hline ------ & 1031 & $1029 ; 979$ & $\begin{array}{l}\text { vC-H pyrrole } 1,2,5 \text { tri- } \\
\text { substituted }\end{array}$ \\
\hline 1016,720 & ----- & ------- & $\mathrm{vC}-\mathrm{H}$ pyrrole $4 \mathrm{H}$ adjacent \\
\hline $1071,896,868,756,688$ & $694,765,837$ & $1069,879,843,759,693$ & $\delta \mathrm{C}-\mathrm{H}$ aromatic out of plane \\
\hline 609,511 & & ------ & $\delta \mathrm{C}-\mathrm{H}$ aromatic in plane \\
\hline
\end{tabular}

C1s

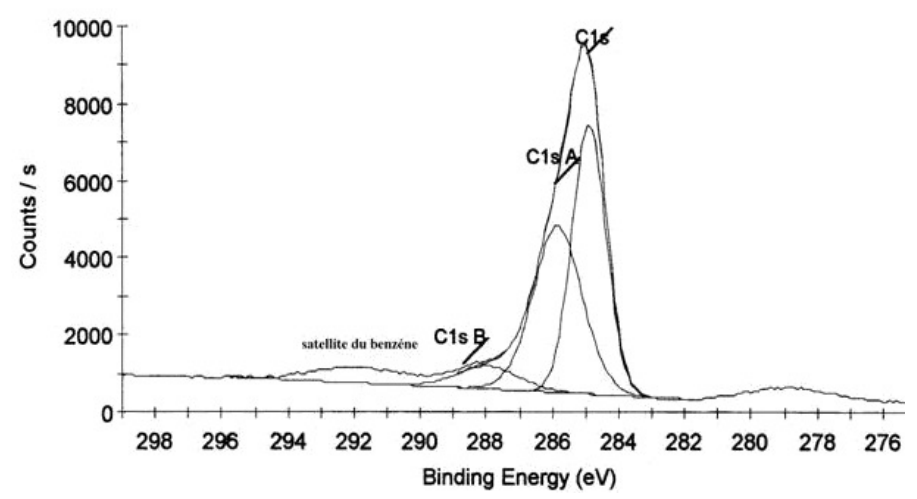

Figure 6. XPS deconvolution peaks of $\mathrm{C} 1 \mathrm{~s}$ of $\mathrm{P} \phi \mathrm{P}$ electrodeposited on $\mathrm{Pt}$ at constant potential $1.3 \mathrm{~V} / \mathrm{SCE}(\mathrm{t}=5 \mathrm{~min}$.). 
XPS analysis. The XPS analysis was performed on $\mathrm{Pt}$ and $\mathrm{Fe}$ electrodes covered by $\mathrm{P} \phi \mathrm{P}$ oxidized films, obtained by the potentiostatic method at constant potential of $1.3 \mathrm{~V} / \mathrm{SCE}(\mathrm{t}=5$ $\mathrm{min})$. The spectra exhibit generally peaks of $\mathrm{F}, \mathrm{O}, \mathrm{C}, \mathrm{S}, \mathrm{N}$, indicating the formation of $\mathrm{P} \phi \mathrm{P}$ film doped with $\mathrm{CF}_{3} \mathrm{SO}_{3}{ }^{-}$anion. The deconvolution of the carbon peak showed the same species (Figure 6), meaning also a similar structure of films electrodeposited on iron and on platinum. The $\mathrm{C} 1 \mathrm{~s}$ spectra displays four peaks, one at 285 corresponding aromatic and aliphatic carbon atoms coupled $(\mathrm{C}-\mathrm{C}, \mathrm{C}=\mathrm{C})$. The second at $286 \mathrm{eV}$ due to the $\mathrm{C}=\mathrm{N}$ and $\mathrm{C}-\mathrm{N}^{+}$. The third one at $288 \mathrm{eV}$ ascribed to $\mathrm{C}=\mathrm{O}$ and $\mathrm{C}=\mathrm{N}^{+}$meaning a film degraded. And the last one at $289 \mathrm{eV}$ is corresponding to the contamination of electrode area by $\mathrm{CO}_{2}$ in air $[6,29-30]$.

\section{Corrosion tests}

In order to explore the possible iron corrosion inhibition properties of the covering $\mathrm{P} \phi \mathrm{P}$ film, we performed linear potential scans at $v=2 \mathrm{mV} / \mathrm{s}$ in a characteristic region, involving only the iron oxidation process, i.e. from -450 to $+450 \mathrm{mV} / \mathrm{SCE}$. In this domain, the doping process does not take place. We used an aqueous $\mathrm{NaCl}$ solution $(3 \%)$. The curve recorded for naked (untreated) iron is considered as a reference (Figure 7). The film was obtained by applying a potential $\mathrm{E}=$ 1.2 V/SCE during $7 \mathrm{~min}$ on iron electrode treated with $10 \% \mathrm{HNO}_{3}$. The $\mathrm{P} \phi \mathrm{P}$-modified iron electrode showed an important decrease of current densities relative to untreated and acid_treated iron electrodes, indicating that the polymer film acts as a barrier for iron dissolution $[7,31]$.

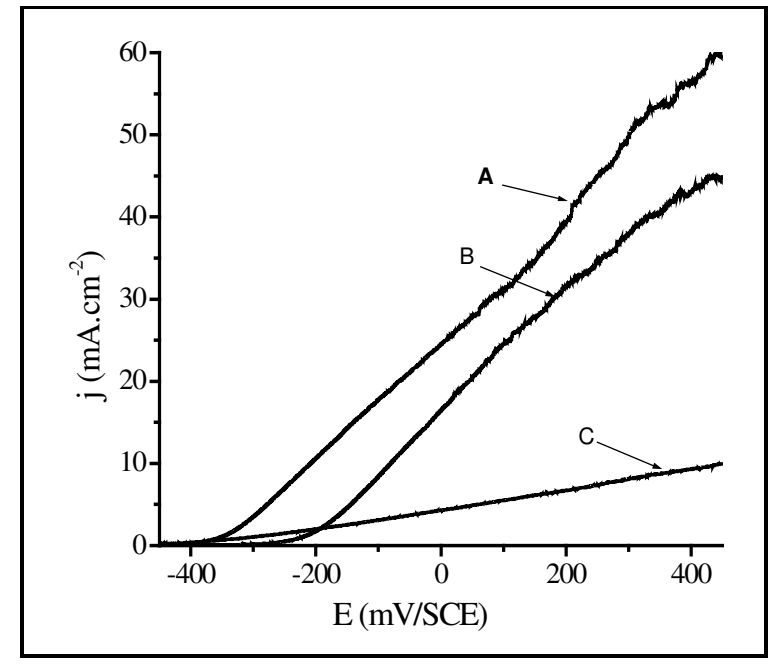

Figure 7. Polarization curves in $\mathrm{NaCl} 3 \%$ aqueous solution of naked iron substrate (A), iron substrate treated with $\mathrm{HNO}_{3} 10 \%$ (B) and iron substrate treated with $\mathrm{HNO}_{3} 10 \%$ and covered with $\mathrm{P} \phi \mathrm{P}(\mathrm{C})$ (the film was obtained by applying $\mathrm{E}=1.2 \mathrm{~V} / \mathrm{SCE}$ during 7 $\min$ ).

\section{CONCLUSIONS}

We have shown that the deposition of poly-N-phenylpyrrole on iron can be successfully realized by the electrochemical means, after pretreatment of the substrate with diluted nitric acid. The 
strong adhesion of $\mathrm{P} \phi \mathrm{P}$ coatings makes the polymer potentially interesting as the barrier action against corrosion. In addition, the rate of the anodic dissolution of the iron electrode can be considerably decreased during the electrochemical polymerization of $\mathrm{N}$-phenylpyrrole. The coverage of the iron is achieved after only five scan cycles. The electrochemical and spectroscopic characterizations of the films obtained on iron and platinum revealed very electroactive, homogeneous and adherent films with a similar structure.

\section{AKNOWLEDGEMENTS}

This work was partly supported by the Third Word Academy of Sciences (TWAS) through a project grant to the Senegalese Research Group in Electrochemistry and Polymer Science (TWAS Research Unit No. 04-050 LDC/CHE/AF/AC).

\section{REFERENCES}

1. Brédas, J.L; Cornil, K.; Meyers, F. in: Skotheim, T.A.; Elsenbaumer, R.L.; Reynolds, J.R.; (Eds.), Handbook of Conducting Polymers, 2nd ed., Marcel Dekker: New York; 1998.

2. Sadki, S.; Chevrot, C. Electrochim. Acta 2003, 48, 733.

3. Wu, J.; Pawliszyn, J. J. Chromatography 2001, 909, 37.

4. Sackmeche, N.; Bazzaoui, E.A.; Fall, M.; Aeiyach, S.; Jouini, M.; Aaron, J.J.; Lacaze, P.C. Synth. Met. 1997, 84, 191.

5. Lee, H.; Yang, H.; Kwak, J. J. Phys. Chem. 1999, B. 103, 6030.

6. Gningue-Sall, D.; Koné, A.; Aaron, J.J.; Aeiyach, S.; Hedayatullah, M.; Lacaze, P.C. Synth. Met. 1996, 82, 119.

7. Deng, Z.; Stone, D.; Thompson, M. Analyst 1997, 122, 1129.

8. Otero, T.F.; Cantero, I. J. Power Sources 1999, 81-82, 2075.

9. Prissanaroon, W.; Ruangchuay, L.; Sirivat, A.; Schwank, J. Synth. Met. 2000, 114, 65.

10. Dimitrakopoulos, C.D.; Mascaro, D.J. IBM J. Res. Dev. 2001, 45, 11.

11. Lallemand, F.; Auguste, D.; Amato, C.; Hevesi, L.; Delhalle, J.; Mekhalif, Z. Electrochim. Acta 2007, 52, 4334.

12. Prissanaroon, W.; Brack, N.; Pigraam, P.J.; Liesegang, J. Synth. Met. 2004, 142, 25.

13. Ferreira, C.A; Domenech, S.C.; Lacaze, P.C. J. Appl. Electrochem. 2000, 31, 49.

14. Ferreira, C.A.; Aeiyach, S.; Delamar, M.; Lacaze, P.C. J. Electroanal. Chem. 1990, 284, 351.

15. Ferreira, C.A.; Aeiyach, S.; Aaron, J.J.; Lacaze, P.C. Electrochim. Acta 1996, 41, 1801.

16. Gningue-Sall, D.; Fall, M.; Dieng, M.M.; Aaron, J.J.; Lacaze, P.C. Phys. Chem. Chem. Phys. 1999, $1,1731$.

17. Robert, C.; Weast P.D. (Eds.), Handbook of Chemistry and Physics, 67th ed., D151-D158, CRC Press: Boca Raton, Florida; 1986-1987.

18. Skotheim, T.A. (Ed.), Handbook of Conducting Polymers, Vol. 1-2, Marcel Dekker: New York; 1986.

19. Ferreira, C.A.; Aeiyach, S.; Delamar, M.; Lacaze, P.C. Surface Inter. Anal. 1993, $20,749$.

20. Preja, J.; Lundstrom, J.; Skotheim, T.A. J. Electrochem. Soc. 1982, 129, 2685.

21. Cheung, K.M.; Bloor, D.; Stevens, G.C. Polymer 1988, 29, 1709.

22. Beck, F.; Michaelis, R. Werkstoffe und Korrosion 1991, 42, 341.

23 Diaw, A.K.D.; Gningue-Sall, D.; Kone, A.; Dione et, G.; Dieng, M.M. J. Soc. Ouest-Afr. Chim. 2006, 21, 77. 
24 Diaw, A.K.D.; Gningue-Sall, D.; Kone et, A.; Dieng, M.M. J. Soc. Ouest-Afr. Chim. 2007, $24,7$.

25. Sakmeche, N.; Aeiyach, S.; Aaron, J.J; Jouini, M.; Lacroix, J.C.; Lacaze, P.C. Langmuir 1999, $15,2566$.

26. Mangeney, C.; Just, P.E.; Lacroix, J.C.; Chane ching, K.I.; Jouini, M.; Aeiyach et, S.; Lacaze, P.C. Synth. Met. 1999, 102, 1313.

27. Mangeney, C.; Lacroix, J.C.; Chane ching, K.I.; Aeiyach, S.; Jouini, M.; Adenier, A.; Lacaze, P.C. Synth. Met. 2000, 108, 237.

28. Socrate, G. Infrared Characteristic Group Frequencies, John Wiley and Sons: New York; 1980.

29. Omastova, M.; Trchova, M.; Pionteck, J.; Prokes, J.; Stejskal, J. Synth. Met. 2004, 143, 153.

30. Boukerman, K.; Omastova, M.; Fedorko, P.; Chehimi, M.M. Applied Surface Science 2005, 249, 303.

31. Nguyen, Thi Le, H.; Garcia, B.; Deslouis, C.; Le Xuan, Q. Electrochim. Acta 2001, 46, 4259. 